\title{
Transcriptional regulation of a yeast HSP70 gene by heat shock factor and an upstream repression site-binding factor
}

\author{
Hay-Oak Park ${ }^{1}$ and Elizabeth A. Craig ${ }^{2}$ \\ Department of Physiological Chemistry, University of Wisconsin-Madison, Madison, Wisconsin 53706 USA
}

\begin{abstract}
SSA1, one of the heat-inducible HSP70 genes in the yeast Saccharomyces cerevisiae, displays a significant basal level of expression under optimal growth conditions. Although multiple sites related to the heat shock element (HSE) consensus sequences are present in the SSA1 promoter region, one of these, HSE2, plays a key role in basal expression. An upsteam repression site (URS) located adjacent to HSE2 causes repression of basal expression but has little effect on heat-inducible expression of SSA1. A series of DNase I footprinting assays suggests that heat shock factor (HSF) and a URS-binding factor (URSF) can bind simultaneously to the adjacent binding sites HSE2 and URS under optimal growth conditions. URSF in extracts from heat-shocked cells does not bind (or binds very poorly) to the URS adjacent to HSE2. However, URSF in these extracts is able to bind the URS if the URS is separated from HSE2 or if the HSE is mutated such that HSF binding is abolished. These in vitro experiments are consistent with in vivo results showing that the URS is able to repress transcription driven by HSE2 both before and after heat shock if it is separated from HSE2. Our results are consistent with a model of repression in which URSF and HSF bind simultaneously to the adjacent binding sites URS and HSE2 prior to heat shock. After heat shock, however, binding of the two proteins to the adjacent sites is exclusive, perhaps due to modification of HSF known to occur upon heat shock. Because HSF binding predominates, repression by URSF is relieved upon heat shock.
\end{abstract}

[Key Words: Heat shock; negative regulation; upsteam repression site-binding factor; heat shock factor; transcription]

Received February 15, 1991; revised version accepted April 3, 1991.

Expression of heat shock genes is induced upon temperature upshift or a variety of other environmental stresses. This gene activation is rapid and transient and, in most cases, appears to be regulated primarily at the transcriptional level (Bienz and Pelham 1987). Transcriptional activation of almost all heat shock genes in eukaryotes requires a highly conserved sequence element, referred to as a heat shock element (HSE). The consensus sequence of HSE was initially proposed to be the 14-bp palindromic sequence CnnGAAnnTTCnnG, where $n$ is any nucleotide (Pelham 1982; Pelham and Bienz 1982). Recently, it has been proposed that an HSE is described more accurately as a DNA element consisting of variable numbers of 5-bp units, nGAAn, in alternating orientation every 5 nucleotides (Amin et al. 1988; Xiao and Lis 1988). A positively acting transcription factor, called heat shock factor (HSF), which binds specifically to the HSEs, has been identified (Parker and Topol 1984; Wu 1984; Kingston et al. 1987; Sorger and Pelham 1987; Weiderrecht et al. 1987). More recently it has been

'Present address: Department of Biochemistry and Biophysics, University of California, San Francisco, California 94143 USA.

${ }^{2}$ Corresponding author. shown that the 5-bp sequence nGAAn is the unit of interaction with HSF (Perisic et al. 1989). It has been proposed that HSF from the yeast Saccharomyces cerevisiae and Drosophila forms a trimer both in solution and when bound to DNA. Oligomerization seems to be essential for high-affinity binding of HSF to DNA (Perisic et al. 1989; Sorger and Nelson 1989).

Yeast HSF can bind to DNA prior to heat shock, whereas in human and Drosophila cells HSF is able to bind to DNA only after heat shock. HSF isolated from heat-shocked yeast cells is more highly phosphorylated than that from control cells, suggesting a modulation of HSF activity by phosphorylation (Sorger et al. 1987; Sorger and Pelham 1988). Thus, it appears that yeast HSF is not regulated at the level of DNA binding; rather, its capacity to activate transcription is regulated by heat shock. Yeast HSF has a low basal activity that is further induced upon heat shock. This is consistent with the fact that the gene encoding yeast HSF is essential at all growth temperatures (Sorger and Pelham 1988; Weiderrecht et al. 1988).

SSA1, one of the heat-inducible HSP70 genes in the yeast $S$. cerevisiae, also displays a significant basal level of expression under optimal growth conditions. The 
structure and regulation of the SSA1 promoter are quite complex. The upsteam promoter region of SSA1 contains multiple sites closely related to the HSE consensus sequence and an upsteam repression site (URS) (Slater and Craig 1987; Park and Craig 1989). Although there are other HSEs in the SSA1 promoter, HSE2 and the URS play key roles in the control of basal expression of the SSA1 gene. A double point mutation in HSE2 abolishes $>80 \%$ of the basal activity of the whole promoter. The URS, located to the $3^{\prime}$ side and just adjacent to HSE2, represses the basal expression but has little effect on heat-inducible expression of the native SSA1 gene. It has been suggested that the basal expression of the SSA1 gene is under negative control mediated by a repressor (Park and Craig 1989).

To gain insights into the mechanism of repression by the URS, we performed a series of experiments, the results of which suggest that HSF and the URS-binding factor (URSF) can bind simultaneously to the adjacent binding sites prior to heat shock. However, in heatshocked cells, the two proteins appear to be unable to bind to the wild-type $S S A 1$ promoter simultaneously; and because HSF binding predominates, repression is relieved.

\section{Results \\ Identification of a protein (URSF) that binds to the URS region by DNase I footprinting and methylation protection experiments}

Previous analyses of deletion and point mutants indicated that an upsteam repression site is located adjacent to HSE2, on its $3^{\prime}$ side, in the SSA1 promoter. By gel-shift assays using a DNA fragment carrying only the URS (from -169 to -194 with respect to transcription start site) we were able to detect a URS-specific binding activity in yeast whole-cell extracts (Park and Craig 1989). To gain insight into the mechanism of repression by the URS, we performed a series of DNase I footprinting analyses using a DNA fragment of the SSA1 promoter (from -261 to -131 ) containing both HSE2 and the URS. Whole-cell extracts were prepared from yeast cells grown at $23^{\circ} \mathrm{C}$, and the HSE- and URS-binding activities were enriched by chromatography on a heparin-Sepharose column. The DNase I protection pattern of the top strand of the wild-type DNA fragment is shown in Figure 1A. The protected region extended from $-170(-174)$ to $-206(-204)$, which includes both HSE2 and the URS (numbers in parentheses indicate uncertainties in the footprint boundaries due to partial protection or to poor cleavage of the DNA at those regions). To determine whether this protection was due to HSF and/or a URSbinding protein, we performed DNase I footprinting analyses using DNA fragments carrying mutations in either HSE2 or the URS (see Fig. 1B), which have been shown previously to destroy either HSE2 or the URS activity in vivo (Park and Craig 1989). The protected region of the top strand of the URS mutant probe extended from -182 to -206 , presumably due to binding of HSF. In contrast, the protected region of the HSE2 mutant probe extended from -170 to -187 , indicating that protection of the URS region is the result of the binding of a distinct URS-binding factor, which we call URSF.

We also observed regions protected from DNase I cleavage both $5^{\prime}$ and $3^{\prime}$ of HSE2 and the URS (Fig. 1A). Because deletions removing these sites did not significantly affect either the basal or heat-inducible expression (Park and Craig 1989), we did not consider proteins binding to these sites in this study. They may be involved in regulation of SSA1 under other conditions.

Because the DNA-binding sites of HSF and URSF determined by DNase I footprinting were not separated from each other, we wanted to gain more detailed insight into these protein-DNA interactions. To determine specific nucleotide contacts of each protein, we performed methylation protection experiments using the wild-type DNA fragments and the same DNA fragments carrying either the HSE2 or URS mutation used in the DNase I footprinting. As shown in Figure 2A, strong protection at one $G(-196)$ and weaker protection at four $G$ residues $(-184,-183,-181$, and -180$)$ were observed with the wild-type top strand. With a probe carrying a mutation in HSE2, the four G residues mentioned above were still protected; with a probe carrying a mutation in the URS, protection at only one $G(-196)$ was observed. A strong protection was observed at two $G$ residues $(-199$ and -189 ) on the wild-type bottom strand (Fig. 2B); no G residues were protected on the bottom strand of the HSE2 mutant probe (data not shown). The results indicate that a $G$ residue $(-196)$ of the top strand and two $G$ residues $(-199$ and -189$)$ of the bottom strand, all of which occur in the HSE consensus sequence, make contact with HSF. Four G residues $(-184,-183,-181$, and -180 ) were protected by URSF. We also observed some weaker protection of $G$ residues at the 3 ' boundary and outside of the region protected by URSF as determined by DNase I footprinting. It is not clear at this point whether this protection is due to some DNA structural change caused by URSF binding or a protein binding at the 3 '-flanking region of the URS.

Initially, proteins were prepared for DNase I footprinting by loading onto the heparin-Sepharose column at 0.1 $\mathrm{M} \mathrm{KCl}$ and then eluting with successive steps of 0.3 and $0.6 \mathrm{M} \mathrm{KCl}$. Most of the HSE- and URS-binding activities were found in the $0.6 \mathrm{M} \mathrm{KCl}$ fraction. Subsequently, we found that the URS- and the HSE-binding activities were partially separated by adding a $0.4 \mathrm{M} \mathrm{KCl}$ elution step in the heparin-Sepharose column fractionation. The URSbinding activity was found in the $0.6 \mathrm{M} \mathrm{KCl}$ fraction from the column, whereas most of the HSE-binding activity was found in the $0.4 \mathrm{M} \mathrm{KCl}$ fraction. The regions protected from DNase I digestion by each fraction were partially overlapping. The URSF-containing fraction protected from -187 to $-174(-170)$ of the top strand (Fig. $3 \mathrm{~A})$ and $-189(-193)$ to $-178(-174)$ of the bottom strand from DNase I cleavage (Fig. 3B). HSF protected from $-206(-204)$ to -182 of the top strand (Fig. 3A) and from -208 to -183 of the bottom strand (Fig. 3B). 

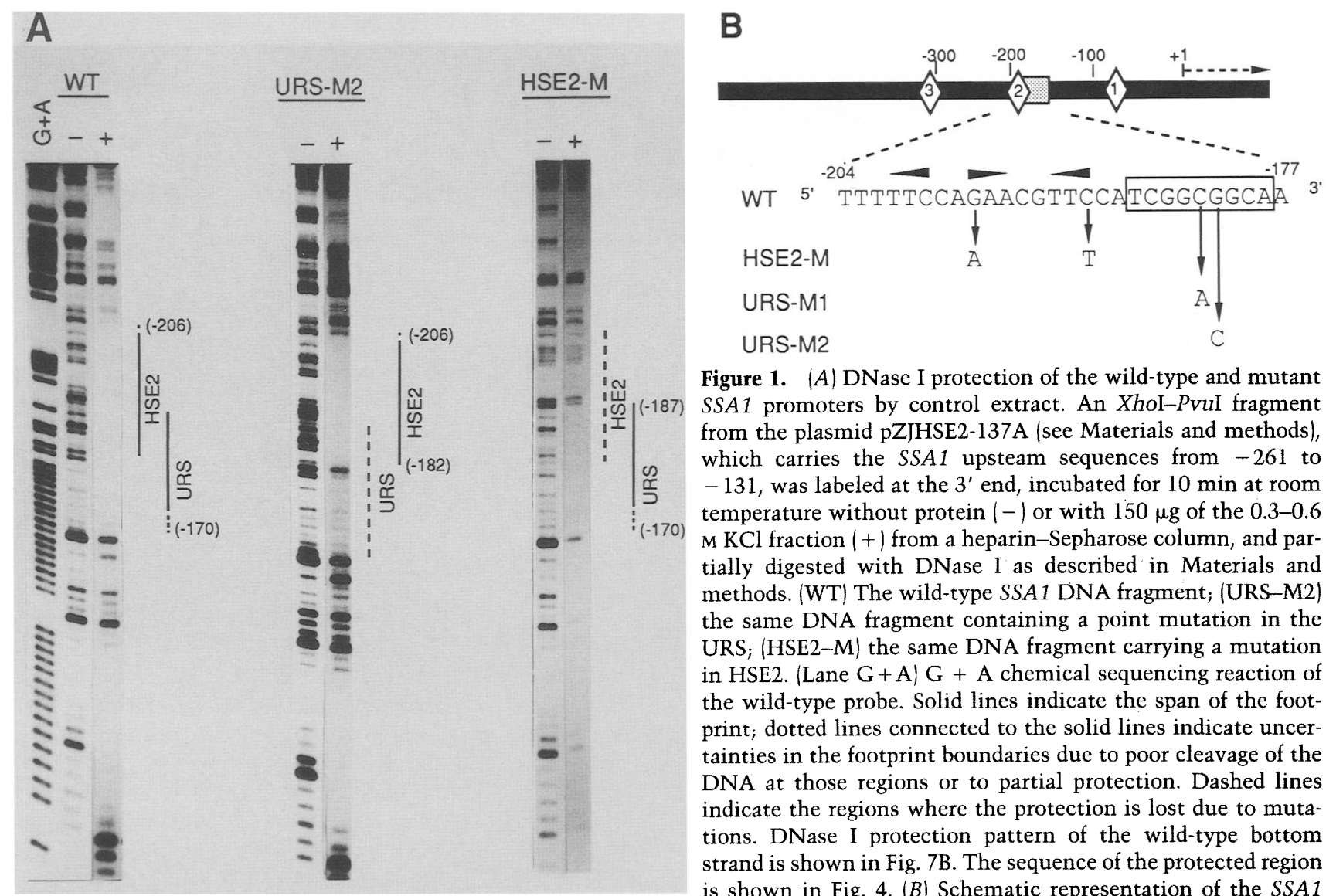

Figure 1. (A) DNase I protection of the wild-type and mutant SSA1 promoters by control extract. An XhoI-PvuI fragment from the plasmid pZJHSE2-137A (see Materials and methods), which carries the SSA1 upsteam sequences from -261 to -131 , was labeled at the $3^{\prime}$ end, incubated for $10 \mathrm{~min}$ at room temperature without protein (-) or with $150 \mu \mathrm{g}$ of the $0.3-0.6$ $\mathrm{M} \mathrm{KCl}$ fraction (+ ) from a heparin-Sepharose column, and partially digested with DNase I as described in Materials and methods. (WT) The wild-type SSA1 DNA fragment; (URS-M2) the same DNA fragment containing a point mutation in the URS; (HSE2-M) the same DNA fragment carrying a mutation in HSE2. (Lane G + A) G + A chemical sequencing reaction of the wild-type probe. Solid lines indicate the span of the footprint; dotted lines connected to the solid lines indicate uncertainties in the footprint boundaries due to poor cleavage of the DNA at those regions or to partial protection. Dashed lines indicate the regions where the protection is lost due to mutations. DNase I protection pattern of the wild-type bottom strand is shown in Fig. 7B. The sequence of the protected region is shown in Fig. 4. (B) Schematic representation of the SSA1 promoter and its mutant derivatives. Each diamond represents an HSE-homologous site (Slater and Craig 1987). The enlarged region shows the sequence of HSE2 and the URS region. (+1) The transcription start site. The long arrowheads mark the component GAA repeats with relative spacing, which has been proposed to comprise a functional HSE (Amin et al. 1988; Xiao and Lis 1988). The box encompasses the consensus sequence of the URS (Luche et a1. 1990). The base substitutions in HSE2 (HSE2-M) and in the URS (URS-M1, URS-M2) are shown below the wild-type (WT) sequence.

This separation of binding activity also supports the idea that different proteins bind to the HSE and URS. A summary of the DNase I footprinting and methylation protection results is shown in Figure 4.

\section{Identification of URSF by UV cross-linking}

To identify URSF directly we performed UV cross-linking experiments using a DNA fragment (from -261 to -131) carrying both HSE2 and the URS as a probe. A protein migrating as a $40-\mathrm{kD}$ polypeptide was detected in the $0.4-0.6 \mathrm{M} \mathrm{KCl}$ fraction that is enriched for URSF (Fig. 5 ). When the same DNA fragment carrying a point mutation in the URS (URS-M2; see Fig. 1B) was used as a probe, this band was not apparent, indicating that this protein was specifically interacting with the URS. Detection of the major $40-\mathrm{kD}$ polypeptide was dependent on the addition of protein and UV radiation. More extensive nuclease digestion of the UV-irradiated binding mixtures did not alter the mobility of this major band. Because the covalent attachment of short oligonucleotides to proteins has only minor effects on the mobility of the proteins in SDS gel, the results indicate that a protein of $M_{\mathrm{r}} 40,000$ binds specifically to the URS.

As an alternative means of identifying URSF, proteins were separated by SDS-PAGE, transferred to nitrocellulose, and probed with a ${ }^{32} \mathrm{P}$-labeled 32 -bp oligonucleotide carrying the URS. A single band of similar size to that obtained by UV cross-linking was detected using extracts prepared from control and heat-shocked cells idata not shown).

We have detected, by DNase I footprinting, other proteins interacting with sites flanking HSE2 and the URS (see Fig. 1A). A major band of $100 \mathrm{kD}$ observed by UV cross-linking with both wild-type and the URS-M2 mutant probe (Fig. 5) could be due to a protein bound to one of these flanking sites, or, alternatively, to nonspecific binding. The protein migrating at $150 \mathrm{kD}$ and giving a weak signal (Fig. 5) is presumably HSF. We observed a stronger band of the same relative molecular mass when the $0.3-0.4 \mathrm{M} \mathrm{KCl}$ fraction (containing most of the HSEbinding activity/ was used, and the $150-\mathrm{kD}$ size is consistent with the apparent relative molecular mass of HSF published previously by another group (Sorger and Pelham 1987). 
A

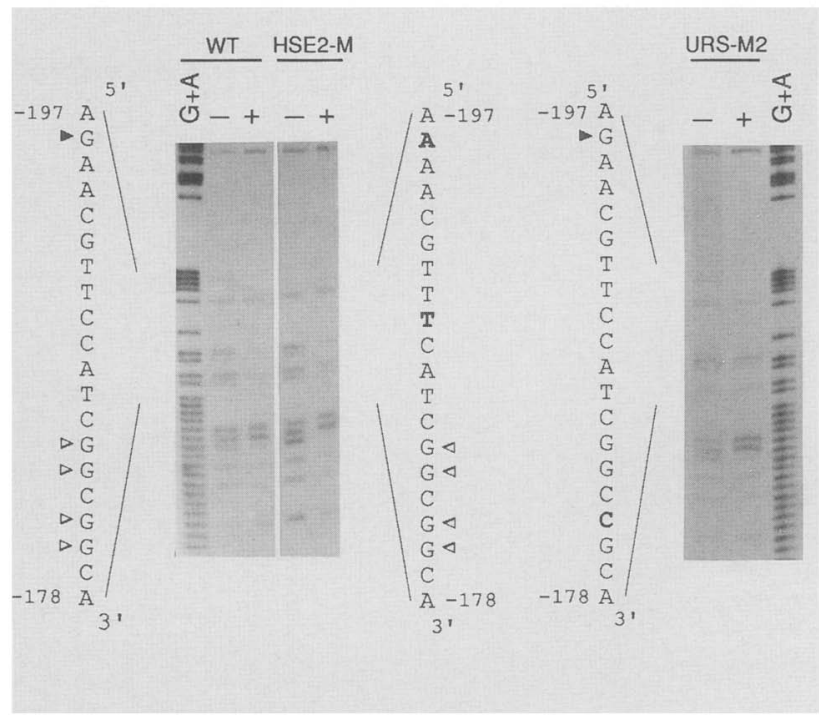

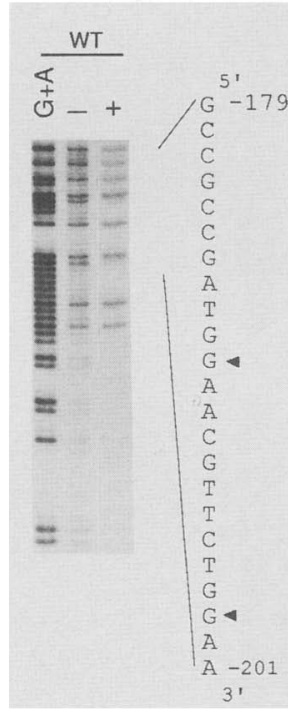

Figure 2. Methylation protection patterns of HSE2 and the URS. DNA methylation protection patterns of SSA1 DNA fragments carrying the wild type (WT), mutations in HSE2 (HSE2-M), or the URS (URS-M2) are shown. (A) Top strand; $(B)$ bottom strand. Positions of methylated G residues that were strongly or weakly protected by the factors are marked by solid or open triangles, respectively. (Lanes $\mathrm{G}+\mathrm{A}$ ) $G+A$ chemical sequencing reactions of the wild-type probe. Bold letters in the sequence indicate the mutated residues. transcription of a heterologous promoter both before and after heat shock (Park and Craig 1989; see also Fig. 6A). The 137-bp DNA fragment of the SSA1 promoter containing both HSE2 and the URS (from -261 to -131 ) was inserted downstream of the CYC1 upsteam activating sequence (UAS) in the CYC1-lacZ fusion vector. Insertion of the 137-bp DNA fragment carrying a mutation in HSE2 but a wild-type URS (HSE2-M) almost completely abolished $C Y C 1$ UAS activity both at $23^{\circ} \mathrm{C}$ and after shift to $37^{\circ} \mathrm{C}$. In contrast, insertion of the $137-\mathrm{bp}$ fragment carrying a mutation in the URS (URS-M1 or URS-M2) did not result in repression of CYC1 transcription (Fig. 6A).

Because the URS could repress expression of a heterologous promoter both before and after heat shock, we decided to test whether the URS could repress transcription driven by HSE2 even after heat shock if it is separated from HSE2. The 137-bp fragment carrying a mutation in HSE2 (HSE2-M) but a wild-type URS was inserted $3^{\prime}$ of HSE2 in the CYC1-lacZ fusion vector, which carries HSE2 in place of the CYC1 UAS. As shown in Figure 6B, CYC1 transcription driven by HSE2 was re-

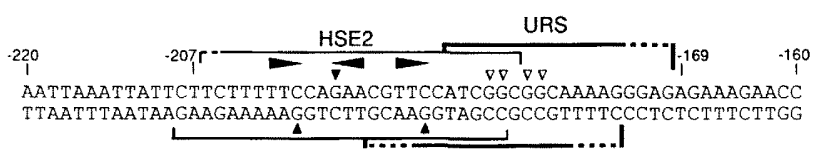

Figure 4. Summary of sequences of HSE2 and the URS region that are protected from DNase I cleavage and methylation by HSF and URSF. Long arrowheads represent repeated GAA blocks within the 5-nucleotide heat shock regulatory module (Amin et al. 1988; Xiao and Lis 1988). Solid lines indicate the span of DNase I footprint; dashed lines indicate uncertainties in the footprint boundaries due to poor cleavage of the DNA at those regions or due to partial protection. Positions of methylated $\mathrm{G}$ residues that were protected by HSF or URSF are marked by small solid or open triangles, respectively. 


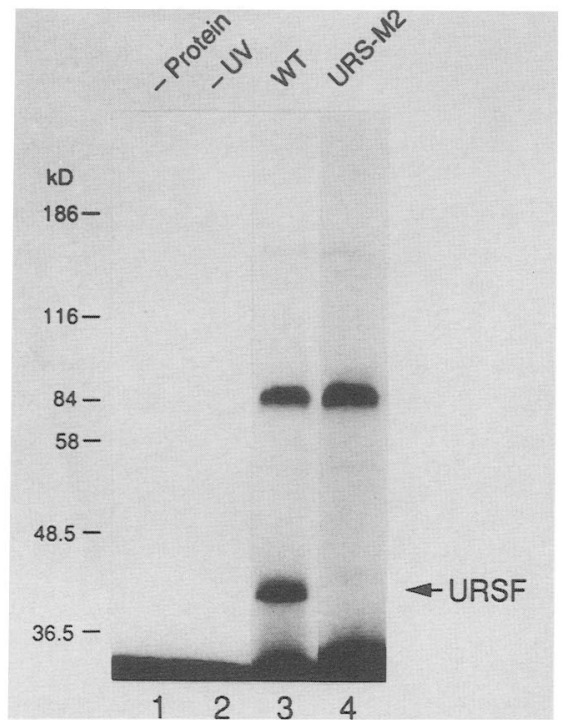

Figure 5. Identification of URSF by UV cross-linking. A wildtype SSA1 promoter fragment (from -261 to -131 ) (lanes $1-3$ ) or its derivative carrying a mutation in the URS (lane 4) was incubated with $60 \mu \mathrm{g}$ of the $0.4-0.6 \mathrm{M} \mathrm{KCl}$ fraction from heparin-Sepharose chromotography. The binding reaction mixtures were UV-irradiated as described in Materials and methods, and the mixture was separated on a polyacrylamide gel. (Lane 1) No protein added; (lane 2) UV irradiation omitted; (lane 3) wild-type probe plus extracts; (lane 4) URS mutant (URS-M2) probe plus extracts. The positions of protein molecular mass markers are indicated at left.

pressed $\sim 18$-fold after heat shock when the URS was separated from HSE2. Although the repression ratio is smaller than that of basal activity, this result indicates that the URS can repress transcription driven by HSE2 after heat shock when it is separated from HSE2. As expected, insertion of the 137-bp fragment carrying a mutation in the URS (URS-M1 or URS-M2) did not result in repression. $\beta$-Galactosidase activities of control and heat-shocked cells carrying these plasmids were elevated compared to the parental plasmid (pZJHSE2-26), probably due to the presence of two copies of HSE in the constructions. Taken together, these results suggest a heat shock-independent mode of repression by the URS if it is separated from HSE2.

\section{Binding of URSF to the URS of the native SSA1 promoter is greatly reduced after heat shock}

To test binding of URSF to the URS in the native SSA1 promoter after heat shock, we performed DNase I footprinting using extracts prepared from heat-shocked cells. Whole-cell extracts were prepared from yeast cells grown at $23^{\circ} \mathrm{C}$ and shifted to $37^{\circ} \mathrm{C}$ for $30 \mathrm{~min}$ prior to harvest, and then fractionated on a heparin-Sepharose column as described above. The $0.3-0.6 \mathrm{M} \mathrm{KCl}$ fraction protected from -206 to -182 of the top strand (Fig. 7A) and from
-208 to -183 of the bottom strand (Fig. 7B) of the wildtype SSA1 promoter fragment (cf. lanes $\mathrm{HS}$ and C). The region protected with heat shock extract from DNase I digestion includes HSE2 and only the $5^{\prime}$ portion of the URS, suggesting that URSF prepared from heat-shocked cells is not able to bind (or binds very poorly) to the native SSA1 promoter. The result is consistent with the fact that, in vivo, the URS represses the basal expression of the SSA1 gene but has little effect on heat-inducible expression (Park and Craig 1989).

However, it was shown by $\beta$-galactosidase assays that the URS can repress transcription driven by HSE2 even after heat shock when it is separated from HSE2 (see above). Thus, we decided to test whether URSF in extracts from heat-shocked cells can bind to the URS by a gel-shift assay. Previously, we showed by gel-shift assays that a protein specifically interacts with the URS. The binding could be competed by addition of excess unlabeled oligonucleotide carrying the URS but not oligonu-
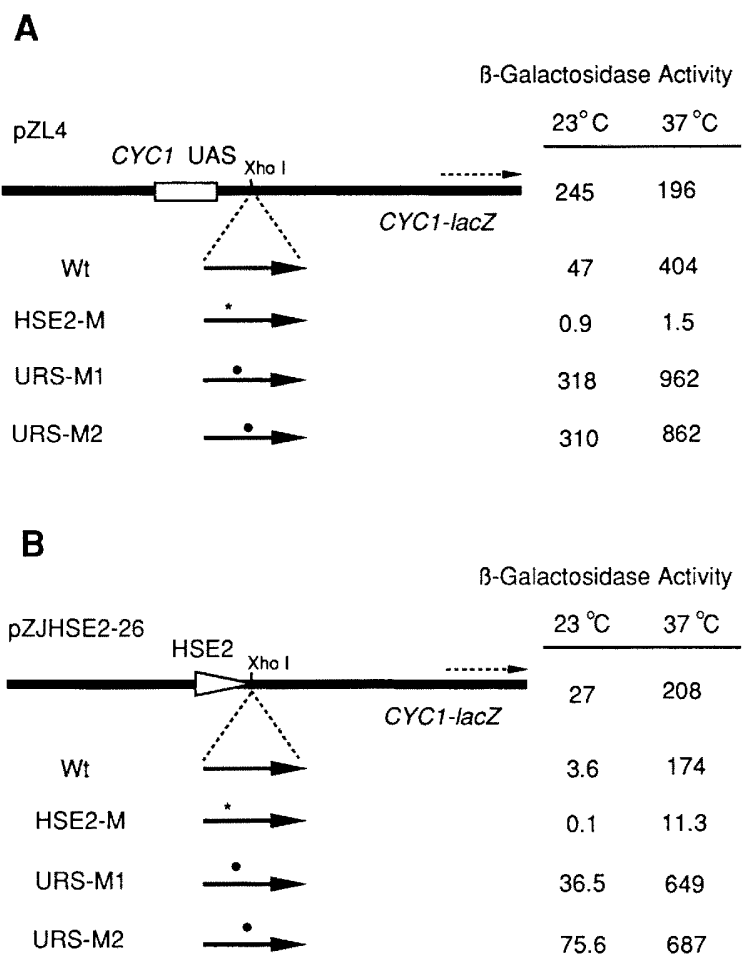

Figure 6. Repression of transcription by the URS when separated from a UAS. $|A|$ The top line shows the promoter region of a CYC1-lacZ fusion vector, pZL4 (Slater and Craig 1987), carrying the CYC1 UASs. The wild-type SSA1 promoter fragment (from -261 to -131 ) and its mutant derivatives were inserted downstream of the CYC1 UASs. $(B)$ The top line shows the promoter region of a CYC1-lacZ fusion vector, pZJHSE2-26 (Slater and Craig 1987), carrying HSE2 of the SSA1 promoter. Cells harboring each of these constructions were grown on glucose-based medium at $23^{\circ} \mathrm{C}$ (basal) or shifted to $37^{\circ} \mathrm{C}$ (heat induced). The heat shock samples were taken $1 \mathrm{hr}$ after the temperature upshift. The asterisk and dot indicate the HSE2 mutation and the URS mutations, respectively, which are shown in Fig. 1B. $\beta$-Galactosidase activities are given for each construction in Miller units. 


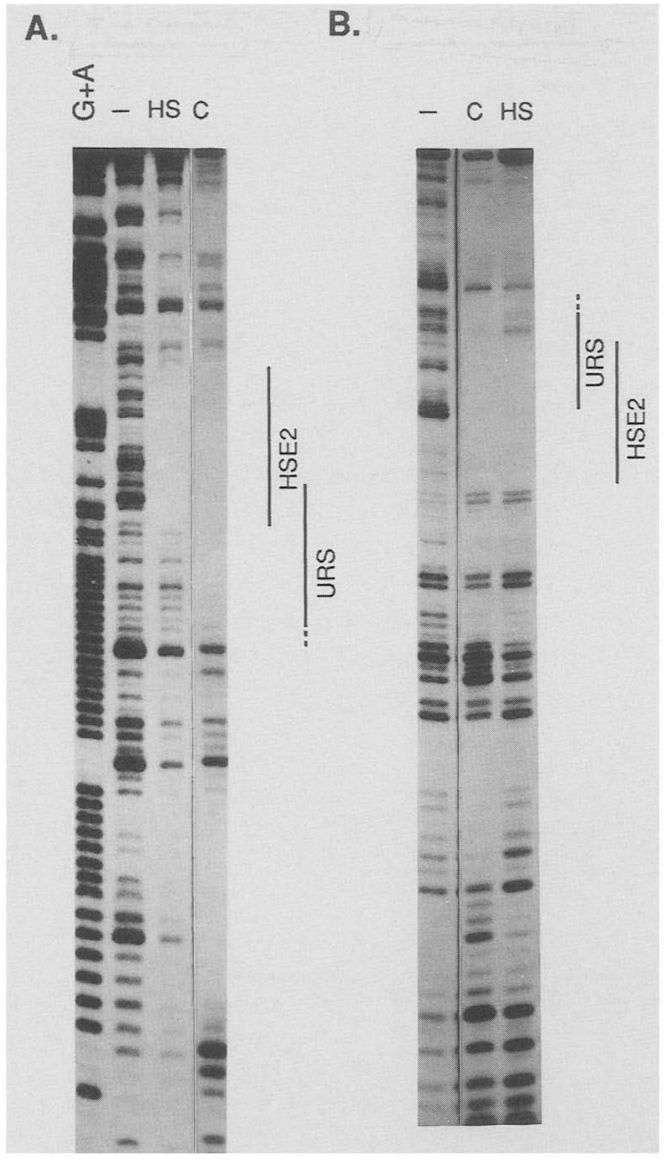

Figure 7. DNase I protection pattern of the $S S A 1$ promoter fragment by control and heat shock extracts. The SSA1 promoter fragment (from -261 to -131 ) was used as a probe (see legend to Fig. 1A). Whole-cell extracts prepared from cells grown at $23^{\circ} \mathrm{C}(\mathrm{C})$ or shifted to $37^{\circ} \mathrm{C}$ for $30 \mathrm{~min}$ prior to harvest (HS) were fractionated on a heparin-Sepharose column as described in Materials and methods. The $0.3-0.6 \mathrm{M} \mathrm{KCl}$ fraction was incubated for $10 \mathrm{~min}$ at room temperature with extract from heat-shocked $(\mathrm{HS})$ or control $(\mathrm{C})$ cells, or without protein $(-) \cdot(G+A) G+A$ chemical sequencing reaction of the probe.

cleotide carrying HSE2 (Park and Craig 1989). A 32-bp fragment containing only the URS (see Materials and methods) was incubated with whole-cell extracts prepared from control (non-heat shock) or heat-shocked cells. The URS-specific protein-DNA complexes with similar mobility shifts were observed using both control and heat shock extracts (Fig. 8A). The binding activity of URSF from control and heat-shocked cells appeared to be very similar because the band intensity of the proteinDNA complex was nearly equal when the same amount of protein was used for each binding reaction. This result indicates that URSF is present in heat shock extracts and can bind to a URS that is separated from HSE2. The magnitude of the band shift caused by URSF from heatshocked and control cells was the same, suggesting no alterations in URSF after heat shock. However, we can- not rule out the possibility that the gel-shift assay failed to resolve any change in the URSF structure.

We also tested, by DNase I footprinting, whether URSF from heat shock extracts can protect a URS region separated from HSE2. An XhoI-RsaI fragment isolated from plasmid pHP104 (see Materials and methods) that contains a 73-bp spacing between the URS and HSE2 was used as a probe for a DNase I footprinting assay. As shown in Figure $8 \mathrm{~B}$, this URS was protected by heat shock extracts, showing that URSF can bind to the URS even after heat shock if it is separated from HSE2. This result is consistent with in vivo results indicating that URS can repress both basal and heat-inducible expression of the construct (see Fig. 6B).

The results discussed so far indicate that after heat shock, URSF cannot bind or binds very poorly to the URS in the native SSA1 promoter, although it can still bind to the URS separated from HSE2. To determine whether URSF in heat shock extracts could bind to the native SSA1 promoter in the absence of HSF binding, we performed a DNase I footprinting analysis with heat shock extracts and a DNA fragment carrying a mutation in HSE2 (HSE2-M) as a probe. As shown in Figure 8C, the URS region of the HSE2 mutant probe was protected from DNase I cleavage by heat shock extract. In contrast, only the HSE2 region was protected with the wild-type probe. Protection of the URS region of the HSE2 mutant probe was indistinguishable when either control or heat shock extracts were used (see Figs. 1A and 8C). Taken together, the results suggest that URSF cannot bind to the URS in the wild-type SSA1 promoter after heat shock because of the binding of HSF nearby.

\section{Discussion \\ URSF, a repressor potentially regulating a variety of yeast promoters}

Using DNase I footprinting and UV cross-linking, we have identified a factor that binds to the URS located very near to HSE2 of the HSP70 gene, SSA1. This URSF has an apparent $M_{\mathrm{r}}$ of 40,000 . In crude extracts, URSF from control cells, but not heat-shocked cells, binds to the URS of the wild-type $S S A 1$ promoter; a single point mutation in the URS diminishes binding of URSF to the site. These results are consistent with effects of the URS on in vivo expression: repression under optimal growth conditions but little effect on expression of SSA1 after heat shock. Therefore, the data strongly suggest that URSF is a repressor regulating the $S S A 1$ gene.

The URS in the SSA1 gene shares strong homology with URS1 in the CAR1 gene. It has been suggested that the CAR1 URS consists of a 9-bp sequence, AGCCGCCGA, based on saturation mutagenesis results (Luche et al. 1990). Our DNase I footprinting assays show that the sequence with one mismatch to the CAR1 URS, in the inverted orientation, is located in the middle of a region protected by URSF from DNase I cleavage. A similar sequence is also present in several other yeast promoters; and in some cases, such as CAR1 and ENO1, it has 


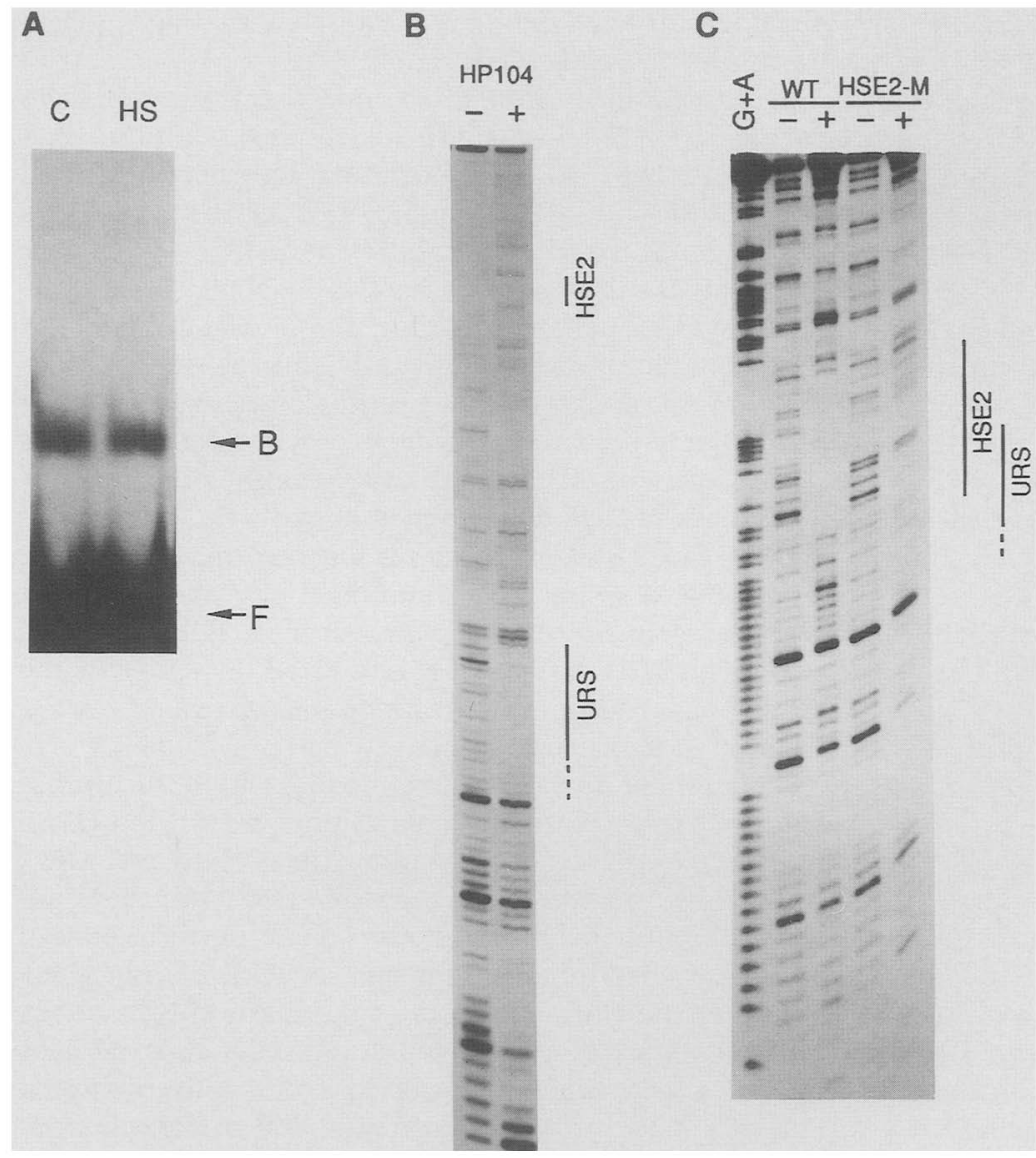

Figure 8. Interaction of URSF from heat-shocked cells with the URS on DNA fragments lacking or having altered HSE. (A) Detection of URSF in the control and heat shock extracts. A gel-shift assay was performed with ${ }^{32} \mathrm{P}$-labeled 32 -bp doublestranded oligonucleotide carrying the URS (see Materials and methods) and $30 \mu \mathrm{g}$ of whole-cell extract prepared from cells grown at $23^{\circ} \mathrm{C}(\mathrm{C})$ or heat-shocked cells (HS). F and B indicate free DNA and protein-bound DNA, respectively. $(B)$ URSF in extracts from heat-shocked cells can bind to a URS separated from HSE2 even after heat shock. An Xhol-RsaI fragment from plasmid pHP104 (see Materials and methods), which carries the wildtype HSE2 separated from the URS by $73 \mathrm{bp}$, was labeled at the $3^{\prime}$ end and incubated without protein (-) or with $100 \mu \mathrm{g}$ of $0.3-0.6 \mathrm{M} \mathrm{KCl}$ fraction $(+1$ prepared from heat-shocked cells. $(C)$ The URS of the SSA1 promoter is protected by URSF from heat-shocked cells when the adjacent HSE2 is mutated. The wild-type SSA1 promoter fragment (from -261 to -131 ) (WT) or a fragment carrying mutations in HSE2 (HSE2-M) (see Fig. 1B) was incubated without protein $|-|$ or with the $0.3-0.6 \mathrm{M}$ fraction $(+)$ prepared from heat-shocked cells and partially digested with DNase I. Equal amounts of protein $(\sim 100 \mu \mathrm{g})$ were used for both lanes WT and HSE2-M. been shown that the sequence is contained in a region associated with negative control of gene expression $1 \mathrm{Co}-$ hen et al. 1987; Sumrada and Cooper 1987). Luche et al. (1990) also reported a protein interacting with the CAR1 URS by gel-shift assays. Competition studies using DNA fragments from the SSA1 promoter indicate that the protein interacting with the CAR1 URS may be the same as the URSF that regulates $S S A 1$. It is therefore possible that the URSF studied here also represses transcription of a variety of yeast genes. However, a family of related proteins might share DNA-binding specificity, but interact specifically with different transcription factors.

\section{Repression of basal transcription of SSAl by the URS}

Two basic mechanisms of repression of transcriptional initiation have been considered. The most commonly observed repression mechanism in prokaryotes involves competition between a repressor protein and general transcription factors such as RNA polymerase for binding to closely placed sites. A related form of competition found in eukaryotes involves competition between a repressor and an activator protein that bind overlapping or closely located sites. In the second type of mechanism, an activator and a repressor bind to nonoverlapping DNA sequences. Protein-protein interactions between the two proteins may prevent the activator from making productive interactions with the general transcription machinery (Levine and Manley 1989).

We performed a series of DNase I footprinting assays with increasing amounts of a fraction containing both HSF and URSF. If the two factors cannot bind at the same time and there is competition between HSF and URSF for binding to the adjacent sites, one would expect to see a partial protection in both the HSE2 and the URS region. However, the HSE2 region became fully saturated even at low protein concentrations, at which point the URS region was only partially protected by URSF (data not shown). A further increase in the amount of total protein resulted in increased protection of the URS region but did not affect protection of HSE2 region by HSF (see Figs. 1A and 7A and B). Thus, DNase I footprinting analyses using control (non-heat shock) extracts indicate that URSF and HSF can bind simultaneously to the HSE2-URS region of the SSA1 promoter. The regions protected by HSF and URSF partially overlap. However, such overlap does not preclude the possibility that both factors bind to the adjacent sites simultaneously, because DNase I may be unable to cleave nucleotides very close to the site of contact of HSF and URSF with the DNA. Methylation protection experiments indicate that 
HSF and URSF do not contact the same nucleotides. We were unable to resolve a guanine HSF-URSF-DNA ternary complex from an HSF-DNA complex by gel-shift assays, perhaps due to the very small size of URSF compared to HSF. HSF appears to bind to DNA as a trimer (Sorger and Nelson 1989), which would contribute $\sim 450$ $\mathrm{kD}$. Our UV cross-linking data suggest that URSF is a protein of only $\sim 40 \mathrm{kD}$.

In conclusion, repression of basal expression of SSA1 does not appear to be caused by URSF preventing the activator HSF from binding to the nearby HSE. It is more likely that URSF inhibits basal transcription by interfering with the function of HSF bound at HSE2, perhaps by preventing proper interaction between HSF and the basic transcription machinery. Alternatively, URSF might inhibit transcription without interacting with HSF, perhaps by affecting looping of the DNA. The data available at this time do not allow us to distinguish between these and other mechanisms of repression.

\section{A model for the lack of repression by URSF after heat shock}

Repression of expression of the SSA1 gene by the URS was seen only prior to heat shock. URSF in extracts prepared from heat-shocked cells binds very poorly to the URS of the wild-type SSA1 promoter as assayed by DNase I footprinting. However, we have shown in three different ways that the DNA-binding ability of URSF is unchanged upon heat shock. First, URS-binding activity was detected in both control and heat shock extracts by a gel-shift assay using an oligonucleotide containing the URS. Second, HSF and URSF in heat shock extracts can bind to their own binding sites when the two sites are separated. Third, DNase I footprinting analyses using an SSA1 promoter DNA carrying an HSE2 mutation showed that URSF can bind to the URS even after heat shock when HSF is no longer able to bind to HSE2. URS can also repress transcription of a heterologous promoter in vivo after heat shock when the URS is not next to a wild-type HSE2. These data are consistent with the idea that there is no apparent change in the DNA-binding ability of URSF upon heat shock and URSF cannot bind to the URS in the wild-type SSA1 promoter after heat shock due to the binding of HSF to HSE2 nearby.

While the activity of HSF is greatly increased upon heat shock, it has been reported that the affinity of HSF for DNA does not change (Sorger et al. 1987). We confirmed this result by a series of gel-shift assays (data not shown). Thus, it is unlikely that the poor binding of URSF to the wild-type $S S A 1$ promoter is due to an increase in HSF binding after heat shock. However, from footprinting assays, it appears that either HSF is more abundant or has a higher affinity for its binding site than that of URSF for the URS (H.-O. Park and E.A. Craig, unpubl.), because complete protection of HSE can be achieved at much lower protein concentrations. Thus, if HSF and URSF cannot bind simultaneously after heat shock, competition for binding between HSF and URSF could result in HSF being the predominant protein bound to the HSE2-URS region.

Although URSF and HSF in control cell extracts were partially separated by heparin-Sepharose column fractionation, HSF in heat-shock extracts cofractionated with URSF (H.-O. Park and E.A. Craig, unpubl.); this might be caused by modification of HSF upon heat shock. It has been shown that HSF isolated from heatshocked yeast cells is more highly phosphorylated than that isolated from control cells (Sorger and Pelham 1988). We have observed by immunoblotting that HSF in our extracts prepared from heat-shocked cells migrates more slowly on SDS gels than that from cells grown at $23^{\circ} \mathrm{C}$ (data not shown), consistent with the altered migration caused by phosphorylation reported previously. Thus, it is tempting to speculate that phosphorylation of HSF is responsible for release from the URS-mediated repression after heat shock, and this coupled with the activation of HSF causes a dramatic increase in SSA1 expression upon heat shock.

We propose the following model, which accommodates our data: Both the control form of HSF and URSF can bind to the adjacent binding sites, HSE2 and URS, prior to heat shock. URSF represses transcription by interfering with the ability of the control form of HSF to activate transcription. After heat shock, modified HSF bound to the HSE2 region does not allow simultaneous binding of the two proteins to the adjacent sites, perhaps due to steric hindrance caused by a conformational change of HSF or charge repulsion due to phosphorylation of HSF that occurs after a heat shock (Fig. 9). Purification of URSF and analysis of possible interactions between HSF and URSF will allow us to understand the mechanism of repression by the URS in more detail.

\section{Materials and methods}

Yeast stains and plasmids

Strain T69 (MATa ura3-52 lys2-801 ade2-101 $\Delta$ trp1) was used as a host for all plasmids for $\beta$-galactosidase assays. Protease-defi-
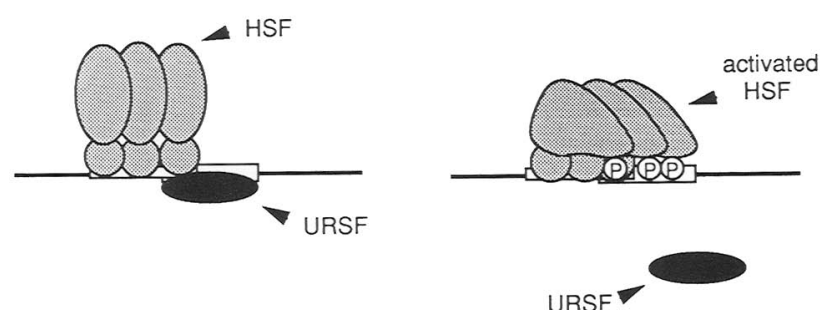

Figure 9. A model for transcriptional repression and derepression of the SSA1 gene by the URS. URSF and HSF can bind simultaneously to the adjacent binding sites prior to heat shock (left, control). Upon heat shock, binding of modified HSF excludes binding of URSF to the adjacent site by steric hindrance or charge repulsion (right, heat shock). $\mathbf{P}$ on the activated HSF indicates phosphorylation of HSF upon heat shock, which has been demonstrated by Sorger and Pelham (1988) (see Discussion). 
cient strain BJ2168 (MATa prb1-1122 pep4-3 prc1-407 leu2 trp1 ura3-52 gal2) was used for extract preparation.

Plasmids pZJHSE2-26 and pZL4 (Fig. 6) were described previously (Slater and Craig 1987). All derivatives of these plasmids were generated by inserting a 137-bp Xhol fragment /containing an SSA1 promoter fragment from -261 to -131 ) carrying either a wild-type or mutated HSE2, or URS. The mutations in HSE2 and the URS have been described previously (Park and Craig 1989) and are also shown in Figure 1B.

Plasmids pZJHSE2-137A and pZJHSE2-137B, used to generate probes for DNase I footprinting assays (see Fig. 1A legend), were constructed by XhoI partial digestion of pZJHSE2-137 (Slater and Craig 1987) and filled in with Klenow, generating a $P v u I$ site. Thus, pZJHSE2-137A or pZJHSE2-137B contains either a downstream or an upstream $X$ hoI site, respectively.

Plasmid pHP104, used to generate a probe used for DNase I footprinting shown in Figure 8B, carries the 137-bp XhoI fragment with the HSE2 mutation (HSE2-M) at the $3^{\prime}$ end of the 26-mer of HSE2.

\section{Enzyme assays}

Yeast cells were transformed with each plasmid and grown on glucose-based synthetic complete media lacking uracil. $\beta$-Galactosidase activity in yeast cells was determined before $\left(23^{\circ} \mathrm{C}\right)$ and after $\left(37^{\circ} \mathrm{C}\right)$ heat shock during logarithmic growth as described previously (Park and Craig 1989).

\section{Extract preparation and heparin-Sepharose column chromatography}

Yeast cells grown in rich, glucose-based media to an $\mathrm{OD}_{600}$ of $1.3-1.5$ at $23^{\circ} \mathrm{C}$ were used for preparation of control extracts, as described (Park and Craig 1989). For preparation of heat shock extracts, cells grown to an $\mathrm{OD}_{600}$ of $0.9-1.0$ at $23^{\circ} \mathrm{C}$ were shifted to $37^{\circ} \mathrm{C}$ for $30 \mathrm{~min}$ prior to harvest. Yeast whole-cell extracts were prepared as described previously (Park and Craig 1989). Whole-cell extracts were loaded directly on a heparin-Sepharose column and washed first with three column volumes of buffer A (20 mM HEPES at pH 8.0,1 $\mathrm{mm} \mathrm{MgCl}_{2}, 0.1 \mathrm{~mm}$ EDTA, $0.5 \mathrm{mM}$ PMSF, $0.2 \mathrm{mM}$ DTT/ containing $0.1 \mathrm{M} \mathrm{KCl}$, and then three column volumes of buffer A containing $0.3 \mathrm{M} \mathrm{KCl}$. Both HSE- and URS-binding activities were eluted with two column volumes of buffer A containing $0.6 \mathrm{M} \mathrm{KCl}$. The $0.3-0.6 \mathrm{M}$ fraction was precipitated with ammonium sulfate, (final $50 \%$ saturation) or concentrated using a Centriprep- 10 concentrator (Amicon, Danvers, MA), and dialyzed overnight against buffer A containing $0.1 \mathrm{M} \mathrm{KCl}$. Following dialysis, insoluble materials were precipitated by centrifugation and the supernatant was stored frozen at $-70^{\circ} \mathrm{C}$. Protein concentrations were determined by the Bradford method (Bradford 1976) using reagents from Bio-Rad.

\section{Gel-shift assays, DNase I footprinting, and methylation} protection analyses

Labeling of DNA fragments for probes and the binding reactions was carried out as described previously (Park and Craig 1989). The 32-bp oligonucleotide, described previously (Park and Craig 1989 ) and used as a probe for gel- shift assays, is shown below:

\section{5'-TCGACACGTTCCATCGGCGGCAAAAGGGAGAC-3' 3'- GTGCAAGGTAGCCGCCGTTTTCCCTCTGAGCT-5'}

A 137-bp XhoI-Pvul fragment from plasmid pZJHSE2-137A / top strand) or pZJHSE2-137B (bottom strand) was used for DNase I footprinting assays. The DNA fragment was labeled at the $3^{\prime}$ end with $\left[\alpha^{-32} \mathrm{P}\right] \mathrm{dCTP}$ and Klenow fragment. For DNase I footprinting analysis shown in Figure $8 \mathrm{~B}$, a 283-bp XhoI-RsaI fragment from plasmid pHP104 was generated by partial XhoI digestion and labeled at the $X h o I$ end. For each binding reaction for DNase I footprinting assays, $0.2-0.5 \mathrm{ng}$ of ${ }^{32} \mathrm{P}$-labeled DNA fragment was incubated with $3 \mu \mathrm{g}$ of poly[d(I-C/I-C)] and 80-150 $\mu \mathrm{g}$ of the $0.3-0.6 \mathrm{M} \mathrm{KCl}$ fraction from a heparin-Sepharose column. The binding reaction was carried out at room temperature for $5-10 \mathrm{~min}$, followed by DNase I digestion usually at room temperature for $1 \mathrm{~min}$. The amount of DNase I (Sigma) was determined empirically and ranged from 20 to $400 \mathrm{ng}$. After DNase I digestion, the mixture was extracted with phenol/chloroform, precipitated with ethanol, and subjected to electrophoresis on a $7 \mathrm{M}$ urea sequencing gel.

For methylation protection analysis, the binding reactions were carried out as described above, followed by partial methylation at the guanine residues, as detailed by Maxam and Gilbert (1977).

\section{UV cross-linking}

Both the wild-type and the URS mutant DNA fragments /carrying the SSA1 promoter sequences from -131 to -261 ) were used as probes for UV cross-linking experiments, which were performed by the method of Chodosh et al. (1986) with slight modifications. The DNA was labeled using Klenow fragment and random primer in the presence of $50 \mu \mathrm{M}$ dATP, dGTP, 5-bromo-2'-deoxyuridine triphosphate (Pharmacia), and $5 \mu \mathrm{M}$ $\left[\alpha^{-32} \mathrm{P}\right] \mathrm{dCTP}$. Protein samples of the $0.4-0.6 \mathrm{M}$ fraction from a heparin-Sepharose column were incubated with $1 \mathrm{ng}$ of uniformly labeled DNA and $3 \mu \mathrm{g}$ of poly[d(I-C/I-C)] in $30 \mu \mathrm{l}$ of binding buffer at room temperature. The mixture in an Eppendorf tube was irradiated under a Fotodyne UV lamp (maximum emission wavelength, $310 \mathrm{~nm}$; maximum intensity, $7000 \mathrm{~mW} /$ $\mathrm{cm}^{2}$ ) at a distance of $4.5 \mathrm{~cm}$ from the UV source. The mixture was brought up to $10 \mathrm{mM} \mathrm{CaCl}_{2}$, and DNA was digested for 30 min at $37^{\circ} \mathrm{C}$ with $3 \mu \mathrm{g}$ of DNase I (Sigma) and 1 unit of micrococcal nuclease (Pharmacia). The mixture was then electrophoresed on an SDS $-7.5 \%$ polyacrylamide gel, and the gel was dried onto $3 \mathrm{M}$ Whatman filter paper and autoradiographed. The positions of protein molecular mass markers were determined by prestained protein markers from Sigma.

\section{Acknowledgments}

We are grateful to Peggy Farnham and Charles Nicolet for critical reading of the manuscript. We also thank Peggy Farnham, Carol Gross, Charles Nicolet, Anna Means, Pil Jung Kang, and Mike Young for helpful discussions during the progress of this work. This work was supported by a U.S. Public Health Service grant from the National Institutes of Health to E.A.C. and by the Lucille P. Markey Charitable Trust, Miami, Florida to H.-O.P.

The publication costs of this article were defrayed in part by payment of page charges. This article must therefore be hereby marked "advertisement" in accordance with 18 USC section 1734 solely to indicate this fact. 


\section{References}

Amin, J., J. Ananthan, and R. Voellmy. 1988. Key features of heat shock regulatory elements. Mol. Cell. Biol. 8: 37613769 .

Bienz, M. and H.R.B. Pelham. 1987. Mechanisms of heat-shock gene activation in higher eucaryotes. Adv. Genet. 24: 31-72.

Bradford, M.M. 1976. A rapid and sensitive method for the quantitation of microgram quantities of protein utilizing the principle of protein dye binding. Anal. Biochem. 72: 248254.

Chodosh, L.A., R.W. Carthew, and P.A. Sharp. 1986. A single polypeptide possesses the binding and transcription activities of the Adenovirus major late transcription factor. Mol. Cell. Biol. 6: 4723-4733.

Cohen, R.C., T. Yokoi, J.P. Holland, A.E. Pepper, and M.J. Holland. 1987. Transcription of the constitutively expressed yeast enolase gene ENO1 is mediated by positive and negative cis acting regulatory sequences. Mol. Cell. Biol. 7: 2753-2761.

Kingston, R., T. Schuetz, and Z. Larin. 1987. Heat-inducible human factor that binds to a human hsp70 promoter. Mol. Cell. Biol. 7: 1530-1534.

Levine, M. and J.L. Manley. 1989. Transcriptional repression of eukaryotic promoters. Cell 59: 405-408.

Luche, R.M., R. Sumrada, and T.G. Cooper. 1990. A cis-acting element present in multiple genes serves as a repressor protein binding site for the yeast CAR1 gene. Mol. Cell. Biol. 10: 3884-3895.

Maxam, A.M. and W. Gilbert. 1977. A new method for sequencing DNA. Proc. Natl. Acad. Sci. 74: 560-564.

Park, H.-O. and E.A. Craig. 1989. Positive and negative regulation of basal expression of a yeast HSP70 gene. Mol. Cell. Biol. 9: 2025-2033.

Parker, C.S. and J. Topol. 1984. A Drosophila RNA polymerase II transcription factor binds to the regulatory site of an hsp70 gene. Cell 37: 273-283.

Pelham, H.R.B. 1982. A regulatory upstream promoter element in the Drosophila hsp70 heat-shock gene. Cell 30: 517-528.

Pelham, H.R.B. and M. Bienz. 1982. A synthetic heat-shock promoter element confers heat inducibility on the herpes simplex virus thymidine kinase gene. EMBO /. 1: 1473-1477.

Perisic, O., H. Xiao and J.T. Lis. 1989. Stable binding of Drosophila heat shock factor to head-to-head and tail-to-tail repeats of a conserved 5 bp recognition unit. Cell 59: 797-806.

Slater, M. and E. Craig. 1987. Transcriptional regulation of an hsp70 heat shock gene in the yeast Saccharomyces cerevisiae. Mol. Cell. Biol. 7: 1906-1916.

Sorger, P.K. and H.C.M. Nelson. 1989. Trimerization of a yeast transcriptional activator via a coiled-coil motif. Cell 59: 807-813.

Sorger, P. and H. Pelham. 1987. Purification and characterization of a heat shock element binding protein from yeast. $E M B O$ \%. 6: 3035-3041.

-1988. Yeast heat shock factor is an essential DNA-binding protein that exhibits temperature-dependent phosphorylation. Cell 39: 855-864.

Sorger, P., M. Lewis, and H. Pelham. 1987. Heat shock factor is regulated differently in yeast and $\mathrm{HeLa}$ cells. Nature 329: $81-84$.

Sumrada, R.A. and T.G. Cooper. 1987. Ubiquitous upstream repression sequences control activation of the inducible arginase gene in yeast. Proc. Natl. Acad. Sci. 84: 3997-4001.

Weiderrecht, G., D. Shuey, W. Kibbe, and C. Parker. 1987. The Saccharomyces and Drosophila heat shock transcription factors are identical in size and DNA binding properties. Cell
48: $507-515$.

Weiderrecht, G., D. Seto, and C. Parker. 1988. Isolation of the gene encoding the $S$. cerevisiae heat shock transcription factor. Cell 54: 841-853.

Wu, C. 1984. Two protein-binding sites in chromatin implicated in the activation of heat-shock genes. Nature 309: 229-234.

Xiao, H. and J.T. Lis. 1988. Germline transformation used to define key features of the heat shock response element. Science 239: 1139-1142. 


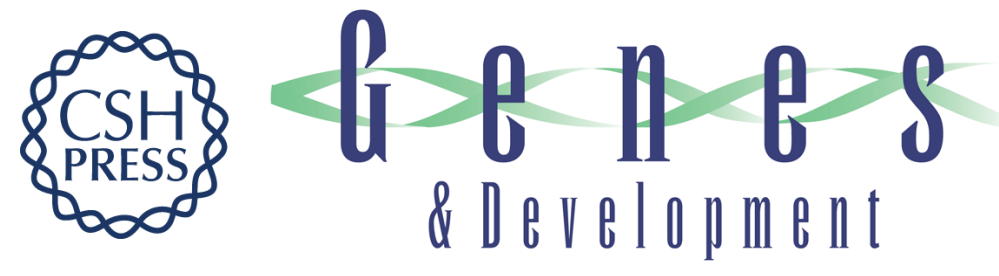

\section{Transcriptional regulation of a yeast HSP70 gene by heat shock factor and an upstream repression site-binding factor.}

H O Park and E A Craig

Genes Dev. 1991, 5:

Access the most recent version at doi:10.1101/gad.5.7.1299

References This article cites 24 articles, 10 of which can be accessed free at: http://genesdev.cshlp.org/content/5/7/1299.full.html\#ref-list-1

License

Email Alerting

Service

Receive free email alerts when new articles cite this article - sign up in the box at the top right corner of the article or click here.

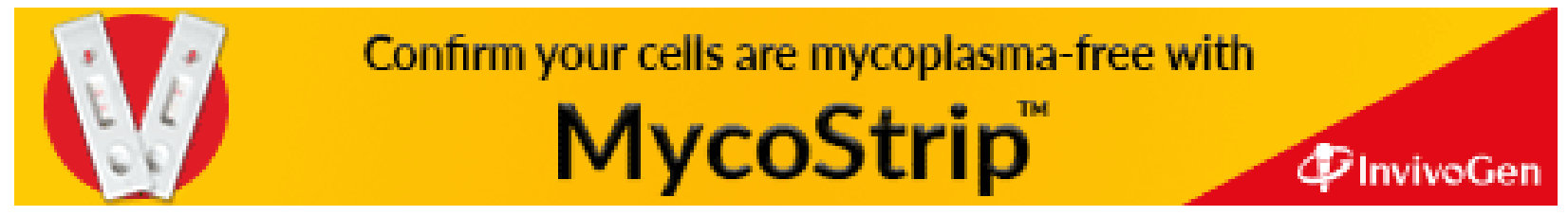

